\title{
O Meças, De Rentes de Carvalho: ROMANCE POLIFÓNICO SOBRE PORTUGAL ${ }^{1,2}$ \\ O Meças, by Rentes de Carvalho: Polyphonic nOVEL ABOUt PoRtugal
}

Carlos Nogueira

Universidade de Vigo

Vigo - Espanha

Em 2013, numa entrevista concedida ao JL - Jornal de Letras, Artes e Ideias, referindo-se ao romance que acabava de publicar, J. Rentes de Carvalho (1930) afirmava: "Creio, aliás, que não voltarei tâo cedo ao género, pois é difícil manter a sequência e evitar que os personagens não baralhem o enredo". O novo romance de J. Rentes de Carvalho não vem necessariamente contradizer aquelas palavras, uma vez que passaram já três anos desde a saída de Mentiras \& Diamantes (2013). Mas não nos parece arriscado dizer que a maioria dos leitores do autor de Ernestina terá recebido com grande surpresa a notícia da publicação de $O$ Meças, o oitavo romance de um escritor que também tem sobressaído na crônica, no conto e no diário.

J. Rentes de Carvalho é um escritor moderno desde o seu primeiro romance, Montedor (1968), reeditado em finais de 2014. Este livro expóe o mundo interior de uma personagem, em discurso de primeira pessoa, mas não descuida a realidade exterior: o contrabando, a emigração, a política obscura e corrupta, a desvergonha e a impunidade dos poderosos, a influência do clero, as desigualdades econômicas e sociais, o atraso sociocultural.

Montedor é um romance psicológico, mas é também um romance de formação de matriz autobiográfica e de ação, e não menos um romance realista que vai buscar os temas e motivos ao quotidiano mais comum e nos revela uma sociedade em conflito. Assistimos a um número significativo de peripécias dramáticas e ao drama interior do protagonista desde o momento em que ele reprova nos exames que lhe dariam acesso a um "diploma" e a um bom emprego, testemunhamos os momentos principais da sua vida, desde a ida para a tropa, ao regresso a casa e ao casamento por obrigação; e somos levados a estabelecer uma comparação com a vida de quem escreveu o livro. J. Rentes de Carvalho deixou Portugal, viveu em cidades como o Rio de Janeiro, Nova Iorque e Paris, e estabeleceu-se na Holanda em 1956,

1 Resenha de Carvalho, J. Rentes de. O Meças, Lisboa: Quetzal, 2016.

2 Esta resenha faz parte dos trabalhos da Cátedra Internacional José Saramago (Universidade de Vigo), projeto POEPOLIT (FFI2016-77584-P, Ministério de Economia e Competitividade da Espanha) e do Programa Estratégico UID/ELT/00500/2013 da FCT (Portugal). 
onde teve condiçóes para desenvolver uma carreira como escritor de méritos rapidamente reconhecidos no país que o recebeu. O protagonista de Montedor ficou em Portugal, e aí, fechado dentro de si, perdeu toda a liberdade e dignidade. Um romance, como se vê, e por razóes óbvias, tão atual na década de sessenta como hoje.

O Meças, como Montedor, é um romance sobre Portugal. Esta fórmula, que tem sido usada para definir a ficção de J. Rentes de Carvalho, apesar de não ser inexata, é muito incompleta. Montedor articula a representação da intimidade mais profunda de uma personagem com a representaçáo dos problemas de Portugal, e estabelece uma relação entre o tempo interior do protagonista e o tempo cronológico do país salazarista. A um tempo histórico e a um quotidiano em que existem figuras que dir-se-ia terem séculos, a um tempo que passa sem que se alterem as questôes que em Portugal parecem ser irremediáveis (o patriarcado, as diferenças e a hostilidade entre ricos e pobres, o atraso sociocultural e econômico, o imobilismo, a corrupção), corresponde o tempo interior vivido pelo narrador-personagem, que é um perdedor atormentado até ao paroxismo. Com diferenças de perspetiva, de intensidade e de técnica narrativa, esta leitura aplica-se a outros romances do autor, em particular a O Rebate (1971) e A Amante Holandesa (2000, Holanda, 2003, Portugal). Mas o que traz originalidade a estes conteúdos é a omnipresença da memória e das emoçôes que afligem o sujeito e se sobrepóem à sua vontade. O Meças, organizado em quatro partes, ou em cinco, se considerarmos as "Anotaçóes" finais, está em consonância com a sensibilidade, o pensamento e escrita de J. Rentes de Carvalho, que tem procurado compreender a origem, o significado, os mecanismos e as expressôes, quer da sua memória e das suas emoçóes, quer da memória e das emoçôes portuguesas (e não só).

No primeiro capítulo, o narrador de terceira pessoa apresenta-nos António Roque, conhecido como o Meças, e é através do seu discurso inquiridor que assistimos à tragédia permanente deste homem violento $\mathrm{e}$ angustiado pela presença inexorável de um passado que se faz presente e futuro devido a uma complexa e incontrolável relação de causa e efeito entre perdas humilhantes e comportamentos, sentimentos e emoçóes induzidos por essas perdas e humilhaçôes. No segundo capítulo, agora em discurso de primeira pessoa assumido pelo meio-irmão de Meças (que não sabe que aquele é seu meio-irmão, filho, como ele, do "Senhor Engenheiro"), a memória, enquanto presença interior hipersensível, é também constante. No terceiro capítulo, regressa o narrador de terceira pessoa, que mais uma vez representa o interior mortificado de Meças, e no quarto volta o meio-irmáo da personagem que dá título ao romance. $\mathrm{O}$ meio-irmão de Meças, que se fixou em Newcastle, vem a Portugal com a intenção de revelar a Meças o que os une, mas, afinal, decide náo o fazer. Educado, civilizado, preso às origens e ao mesmo tempo 
distante ou distanciado delas, ele é também, por circunstâncias diversas (o caráter violento do pai, ter-se visto a "crescer sozinho", como ele próprio diz, saber-se nascido num país corrupto e atrasado), assaltado pela memória involuntária (Bergson) e dolorosa.

O Meças, que recebeu o prémio de Melhor Livro de Ficção, relativo a 2016, da Sociedade Portuguesa de Autores (SPA), como toda a obra ficcional deste autor, representa as emoçóes e as memórias repentinas e avassaladoras de personagens portuguesas, e indaga e explora a sua raiz, os seus sentidos e as suas implicaçôes. $\mathrm{O}$ meio opressivo e opressor português está na origem das emoçôes e das memórias dos dois meios-irmãos deste livro, um culto e bem-educado, o outro precisamente o oposto. $O$ Meças é uma representação de grande parte da sociedade portuguesa de meados do século $\mathrm{XX}$ até aos nossos dias, ou da sociedade portuguesa de qualquer tempo e de qualquer lugar. As personagens do romance não encontraram soluçôes para o seu desassossego, mas podem ajudar-nos a ver Portugal mais em profundidade, a compreender as inquietaçóes, as memórias e as respostas da chamada, num sentido muito amplo, portugalidade.

Nem simplesmente realista à maneira de Eça de Queirós, nem exclusivamente subordinado aos procedimentos da narrativa anglo-saxônica (em cuja feição realista, que vem já do século XVIII, entram a sobriedade estilística e a valorização da interioridade das personagens), nem incondicionalmente subordinado às técnicas do noveau roman francês (que, por exemplo, num tempo de crise humanista, elimina ou reduz ao mínimo a intriga, e marca a impossibilidade de construir uma personagem bem delineada), O Meças encerra um conhecimento vasto da literatura portuguesa e internacional, e impóe-se como um livro singular que participa na modernidade da ficção portuguesa, tal como Montedor participou na década de sessenta na renovação literária portuguesa.

Não existe contradição entre a clareza e a exatidão e o registo predominantemente emotivo. O equilíbrio e a disciplina clássica da linguagem de $O$ Meças estáo perfeitamente de acordo com o estilo que reconhecemos a J. Rentes de Carvalho. A musicalidade intrínseca à escrita deste autor impede-a de incorrer em monotonia e automatismo, e em $O$ Meças essa harmonia resulta numa expressão em que despojamento e inquietude se combinam e alternam. A sequência mais comum deste romance inclui oraçóes ou expressôes próprias do escritor clássico que o autor de Ernestina é, e momentos, consideravelmente extensos, em que a emotividade da personagem domina, representada pelo discurso indireto livre e/ou pelo monólogo interior. Esta sobriedade e esta emotividade acolhem, não raramente, um discurso autoirônico, como dissemos, mas também irônico, cômico e satírico cujo alvo é a sociedade em geral, das classes economicamente mais favorecidas às mais baixas, e da unidade da 
família à ética sexual e às estruturas e comportamentos religiosos. Mais do que de humor deve falar-se de comédia trágica, de desconstrução, através de uma paródia relativamente discreta, dos preconceitos e das verdades da sociedade portuguesa de meados do século XX: «Alguns até parece que nascem doutores, e ele, vinte e tal anos na Alemanha, nem sequer a língua foi capaz de aprender, só palavras soltas, os colegas às gargalhadas, obrigando-o a repetir tudo, dizendo que ninguém o entendia e a chamar-lhe "turco"” (p. 107).

$O$ Meças combina a representação da intimidade mais recôndita de duas personagens com a representação discreta mas perceptível dos problemas de Portugal, e estabelece uma relação entre o tempo interior dos protagonistas e o tempo cronológico do país em que eles vivem ou viveram. Prevalece o conhecimento do mundo íntimo das personagens, ora em discurso de terceira pessoa, ora de primeira pessoa, mas não se perde a noção da realidade exterior (a emigração, a política obscura e corrupta ou a influência do clero, por exemplo), que, aliás, determina a desintegração das personalidades que, no caso da personagem Meças, vemos em desequilíbrio psicológico desde o início do romance. A um tempo histórico e a um quotidiano em que se inscrevem figuras que parecem ter séculos, indiferentes ao tempo do calendário, a um tempo que passa sem que mudem as questóes que em Portugal parecem ser insolúveis (as diferenças entre ricos e pobres, e o atraso sociocultural e econômico, essencialmente), correspondem os tempos interiores vividos pelos narradores-personagens, que nos surgem como uma consciência e um corpo angustiados até ao paroxismo. Todo o romance é um prolongamento do primeiro parágrafo:

Alguém terá de lhe emprestar as palavras, porque as desconhece, mas se lhas tivessem ensinado seria incapaz de dizê-las, estonteado pelo remoinho, a vida a desfilar em ondas de desespero, ocasióes falhadas, sempre ele o que perde, a sofrer envergonhado, o que baixa os olhos e até si próprio tem de fugir. (p. 9)

\section{Referências Bibliográficas}

CARVALHO, J. Rentes de. O Meças, Lisboa: Quetzal, 2016. 